\title{
Using time series simulation tool for assessing the effects of variable renewable energy generation on power and energy systems
}

Koivisto, Matti Juhani; Das, Kaushik; Guo, Feng; Sørensen, Poul; Nuño, Edgar; Cutululis, Nicolaos Antonio; Maule, Petr

Published in:

Wiley Interdisciplinary Reviews: Energy and Environment

Link to article, DOI:

10.1002/wene.329

Publication date:

2019

Document Version

Peer reviewed version

Link back to DTU Orbit

Citation $(A P A)$ :

Koivisto, M. J., Das, K., Guo, F., Sørensen, P., Nuño, E., Cutululis, N. A., \& Maule, P. (2019). Using time series simulation tool for assessing the effects of variable renewable energy generation on power and energy systems. Wiley Interdisciplinary Reviews: Energy and Environment, 8(3), [e329]. https://doi.org/10.1002/wene.329

\section{General rights}

Copyright and moral rights for the publications made accessible in the public portal are retained by the authors and/or other copyright owners and it is a condition of accessing publications that users recognise and abide by the legal requirements associated with these rights.

- Users may download and print one copy of any publication from the public portal for the purpose of private study or research.

- You may not further distribute the material or use it for any profit-making activity or commercial gain

- You may freely distribute the URL identifying the publication in the public portal 


\section{Using time series simulation tool for assessing the effects of variable renewable energy generation on power and energy systems}

Authors:

\begin{tabular}{|l|}
\hline First author \\
*Matti Koivisto, orcid.org/0000-0001-6421-7047, Department of Wind Energy, Technical \\
University of Denmark, Roskilde, Denmark, mkoi@dtu.dk \\
\hline Second author \\
Kaushik Das, orcid.org/0000-0002-6501-7896, Department of Wind Energy, Technical \\
University of Denmark, Roskilde, Denmark \\
\hline Third author \\
Feng Guo, Department of Wind Energy, Technical University of Denmark, Roskilde, \\
Denmark \\
\hline Fourth author \\
Poul Sørensen, orcid.org/0000-0001-5612-6284, Department of Wind Energy, Technical \\
University of Denmark, Roskilde, Denmark \\
\hline Fifth author \\
Edgar Nuño, orcid.org/0000-0003-0978-7711, Department of Wind Energy, Technical \\
University of Denmark, Roskilde, Denmark \\
\hline Sixth author \\
Nicolaos Cutululis, orcid.org/0000-0003-2438-1429, Department of Wind Energy, \\
Technical University of Denmark, Roskilde, Denmark \\
\hline Seventh author \\
Petr Maule, Department of Wind Energy, Technical University of Denmark, Roskilde, \\
Denmark
\end{tabular}

*) corresponding author

\section{Abstract}

The increasing share of variable renewable energy (VRE) generation poses challenges to power systems. Possible challenges include adequacy of reserves, planning and operation of power systems, and interconnection expansion studies in future power systems with very different generation patterns compared to today. To meet these challenges, there is a need to develop models and tools to analyse the variability and uncertainty in VRE generation. To address the varied needs, the tools should be versatile and applicable to different geographical and temporal scales. Time series simulation tools can be used to model both today and future scenarios with varying VRE installations. CorRES (Correlations in Renewable Energy Sources) is a simulation tool developed at Technical University of Denmark, Department of Wind Energy capable of simulating both wind and solar generation. It uses a unique combination of meteorological time series and stochastic simulations to provide consistent VRE generation and forecast error time series with temporal resolution in the minute scale. Such simulated VRE time series can be used in addressing the challenges posed by the increasing share of VRE generation. These capabilities will be demonstrated through three case studies: one about the use of large-scale VRE generation simulations in energy system analysis, and two about the use of the simulations in power system operation, planning and analysis. 


\section{Introduction}

In the study of modern power and energy systems, understanding the behaviour of variable renewable energy (VRE) generation is crucial. To analyse the variability and uncertainty in VRE generation, versatile models and tools that can be applied on different temporal and geographical scales are required. Much can be learned about the characteristics of VRE generation by analysing historical data [1], [2], [3]. For the study of future scenarios, the models need to be applicable to a changing geographical distribution and technological development of installations. VRE generation time series for future scenarios can be generated using stochastic time series simulation [4], [5], [6], or meteorological reanalysis techniques (i.e., using historical weather data) [7], [8], [9], [10]. Such VRE generation simulation tools can be used, e.g., in the estimation of adequacy of reserves in power systems [11], in stability analyses [12], in long-term transmission system planning [7], and in electricity market studies [13]. These modelling approaches will be presented in the section Time series simulation for analysing the effects of variable renewable generation. Both approaches allow simulation of long time series (tens of years). The section discusses also electricity load time series that are required in the analysis of residual load (load subtracted by VRE generation).

This paper presents several case studies showing how VRE time series simulation can be applied, using the CorRES (Correlations in Renewable Energy Sources) software as example. It adds newly developed solar photovoltaic (PV) simulation capabilities to the previously developed CorWind software, created for analysing variability in wind generation. The section Combination of meteorological data and stochastic simulations describes how meteorological reanalysis techniques and stochastic simulation are combined to generate wind and solar PV time series for current and future scenarios. The combination of reanalysis data and stochastic simulation is an addition to the literature. The capabilities of the presented methodology to generate wind and solar PV generation time series over a large geographical area are shown in [8], where a novel data-driven solar PV conversion model is also presented. In addition to representative generation time series, the software can simulate forecast errors. The developed forecast error simulation model for solar PV generation is an addition to the literature [14], [15].

To display the versatility of applications where VRE time series simulation can be used, three case studies are presented: one in the section Case 1: Simulating large-scale wind and solar PV generation for energy system analysis, and two in the section Application of Simulated large-scale wind and solar PV generation for power system operation, planning and analysis. In addition to showing distinct applications, the examples demonstrate how VRE generation simulation can be applied on different time-scales (from multiple years of hourly data to focus on a one-minute resolution), and on different geographical areas (Northern Europe in the first, Continental Europe in the second and Western Denmark in the third). The last two sections provide further discussion and conclude the paper.

\section{TIME SERIES SIMULATION FOR ANALYSING THE EFFECTS OF VARIABLE RENEWABLE GENERATION}

This section starts by describing VRE generation forecasting, simulation and forecast error simulation, and their differences in relation to aims and requirements for modelling. Different VRE time series simulation approaches are then presented, and a discussion on load time series is given. 


\section{Simulation and forecasting}

Although, e.g., some multivariate time series models can be used in both simulation and forecasting [16], the aims of these two are quite different. Forecasting of VRE generation is applied usually in the short term (up to a day or a few ahead), whereas simulation is often used to generate long time series (perhaps tens of years). The capability to represent statistical properties, such as variances and correlations, realistically is crucial in simulation. This contrasts with the capability to model short-term conditional expected value starting from a specific point in time, which is usually the main aim in forecasting.

The conditional expected value, i.e., mean, of a time series can often be predicted using the past values of the time series. The conditional mean can be denoted as $\mathrm{E}\left(y_{t+1} \mid H_{t}\right)$, where $H_{t}$ is the history of the process available when making a forecast for time $t+1$. Of course, forecasting can be applied also to more than one-step-ahead. If probabilistic forecasting is applied, higher statistical moments such as variance can also be estimated. VRE forecasting can be done, e.g., using meteorological models, stochastic time series models and neural networks [16], [17], [18].

In simulation, the aim is often to estimate, e.g., probability density functions (PDFs) of different variables. PDF describes the probability of a random variable to reach different values. As an example, one can be interested in estimating the probability of aggregate wind and solar PV generation being less than $10 \%$ of their installed capacity. As the probability distributions of wind and solar generation are non-Gaussian (i.e., not normally distributed), such modelling requires attention to higher moments than the most common expected value and variance. As will be explained in the next subsection, both meteorological reanalysis models and stochastic time series models can be used in simulating long VRE generation time series.

Forecast error simulation aims to represent the uncertainty in VRE generation. Although it is possible to use meteorological models in forecast error simulation via ensemble forecasting [17], it can be computationally demanding. Stochastic time series simulation provides a fast and computationally efficient way of generating statistically representative forecast error time series [14], [15], [19]. As with the VRE generation simulation, forecast error simulation is not focusing on a forecast starting from a specific point in time $H_{t}$. Rather; it aims to generate large amounts of simulations that represent the statistical properties of forecast errors realistically.

\section{Different approaches for VRE generation simulation}

Two main approaches for VRE generation simulation use either meteorological reanalysis models for generating the underlying meteorological fields, or stochastic time series models for simulating the time series of interest. The reanalysis approach is based on past weather, but it can be applied imposing a chosen set of VRE installations on historical meteorological data [7], [8], [9], [10], [20], [21], [22], [23]. This allows the study of both current and future VRE installation scenarios.

Depending on the amount of available reanalysis data, the simulation can provide tens of years of VRE generation time series. As the reanalysis approach is based on past data, the effects of interesting historical meteorological cases can be tested in different scenarios. For example, past storm events can be simulated, as is done in the third case study in this paper. 
Stochastic time series models can simulate large amounts of data quickly. Usually the simulations are based on a time series model, estimated on measured data, which represents both temporal and spatial dependencies. The models can be used to simulate directly generation data or the underlying meteorological data, and they can be applied to current and future scenarios with varying VRE installations [5], [6]. Data transformations are often required because the modelled data are nonGaussian [4]. While the stochastic time series simulations can represent the important statistical characteristics in VRE generation, the simulations do not relate to any exact historical weather patterns, and behaviour, e.g., in rare storm cases cannot be verified directly. Forecast error simulations are often carried out using stochastic time series models [19], [14], [15]. The presented methodology uses both meteorological data and stochastic simulations, as will be presented in the next main section.

\section{Load time series}

This paper focuses on VRE generation simulation. However, to assess the effects of increasing VRE generation on the power and energy systems, the electricity load needs to be analysed as well. For example, when looking at the role of hydro [24] or gas-fired generation in the future, the most important variable is usually not the VRE generation per se, but the behaviour of the residual load [25], [26].

As time series, solar PV generation, wind generation and load behave very differently. As shown, e.g., in [27], a very significant part of the variability in load can often be explained by exogenous explanatory variables, such as temperature or the amount of daylight. Load usually shows a strong diurnal structure with working days and holidays having a different pattern. This leads to a relatively predictable load profile throughout the year, with a winter peak and summer low in the Nordic countries, as seen in Figure 4. Although there are diurnal and seasonal structures in wind generation (their strength depends on the part of the world being studied), in the Nordic countries wind generation can be very low or high at any hour of the year. For solar PV, the clear-sky power profile (i.e., generation with no clouds) can be considered non-stochastic, but the actual generation varies between zero and the possible maximum generation [6]. The section Case 1: Simulating large-scale wind and solar PV generation for energy system analysis discusses the behaviour of residual load in different scenarios.

In the first case study, a historical load time series is used. This approach ensures the load to be correlated with the weather patterns in the simulated solar PV and wind generation (because the meteorological time series are based on a reanalysis of past weather, as will be shown in the next section). However, future use of load modelling and simulation is discussed in the section Extension of the first case study.

\section{COMBINATION OF METEOROLOGICAL DATA AND STOCHASTIC SIMULATIONS}

This section describes the CorRES software, which is based on time series data from a meteorological mesoscale model. However, the methodology includes also stochastic simulations to provide intrahour time series and forecast error simulations. 


\section{Overview}

A block diagram of the main parts of CorRES is shown in Figure 1. The following subsections describe in more detail the meteorological data that are used, the role of the fluctuations and the forecast error simulations. Conversion to power used in CorRES is explained in [8].

As can be seen in Figure 1, CorRES uses both meteorological data and stochastic simulations. The combination of WRF reanalysis data and fluctuation simulations, to better represent the temporal dependencies in wind generation, is an addition to the literature; more details are given in the subsection Fluctuations. The capability of the CorRES methodology to generate joint wind and solar time series over a large transcontinental system is presented in [8], with results validated for different climatic areas; the presented data-driven solar PV conversion model is an addition to the literature.

The combination of capabilities to simulate both available wind generation and forecasts over a large geographical area in CorRES is an extension of previously available methodologies described in the section Different approaches for VRE generation simulation. Applications of these capabilities are shown in the section Application of Simulated large-scale wind and solar PV generation for power system operation, planning and analysis. The forecast error simulation model created for solar PV analyses in CorRES [14], [15] is an addition to existing literature.

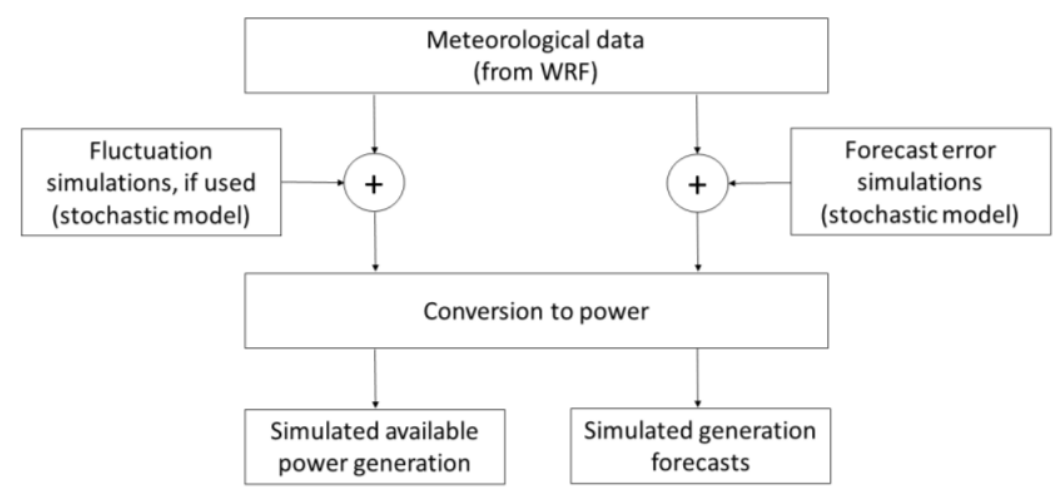

Figure 1: A block diagram of the main parts of CorRES. Simulated available power generation means the generation before, e.g., curtailment.

\section{Meteorological data}

CorRES is based on meteorological data obtained from the Weather Research and Forecasting (WRF) model, a mesoscale modelling system [28]. The mesoscale downscaling method presented in [29], [30] has been used to generate time series of wind speed, irradiance, and other meteorological fields. The simulations are a reanalysis of past weather. Initial, boundary and grids for nudging the WRF simulations were supplied by the European Reanalysis (ERA) Interim Reanalysis [31].

From the WRF model, hourly meteorological time series are obtained on a $10 \mathrm{~km} \times 10 \mathrm{~km}$ grid that covers the area of interest (e.g., Northern Europe). Such a grid of data allows modelling of wind and solar PV generation both today and in future scenarios with a changing geographical distribution of installations. Currently, 34 years of WRF data are available for CorRES simulations. 


\section{Fluctuations}

In [32], [33], it is described that for simulated winds from mesoscale models, variations are smoothened because of spatial and temporal averaging effects. Mesoscale weather models, e.g., WRF, generally underestimate the short-term variability in wind speeds [33]. To generate more realistic simulations, CorRES adds fluctuations to the WRF wind speeds. The fluctuation modelling, based on [34], ensures both realistic power spectral densities for wind speeds in individual locations and coherence functions between the locations. The fluctuations are simulated as stochastic time series that are added to the WRF data, as shown in Figure 1. The fluctuation simulations have expected value of zero, so adding the fluctuations do not change long-term mean wind speeds acquired from WRF. Importantly, fluctuation modelling allows simulation of intra-hour time series by adding realistic short-term variability to the hourly WRF data, which is essential in the case studies presented in the section Application of Simulated large-scale wind and solar PV generation for power system operation, planning and analysis.

As shown in [35], the detailed modelling of fluctuations is specifically important in the analysis of large offshore wind power plants, compared to a dispersed set of wind installations onshore. This is mainly because offshore wind power plants are usually concentrated in a small area where the wind speed fluctuations are highly correlated. Another reason given in [35] is that meteorological conditions may be different offshore than onshore. These are, of course, general observations; CorRES allows fluctuation modelling for both onshore and offshore wind generation. The required addition of fluctuations on WRF data mostly affects time-scales from a few minutes to a few hours [33]. The effect of the fluctuations is less significant when looking at the aggregate of an entire country or of multiple countries.

\section{Forecast error simulation}

In addition to fluctuations, forecast errors in CorRES are simulated as a stochastic process. Following [19], the forecast errors in wind speeds are modelled as a vector autoregressive moving-average model; this gives simulated errors that have both realistic temporal characteristics and are correlated between the different locations. As shown in Figure 1, the forecast errors are added onto the WRF data to reach simulated forecast time series. The forecast error simulation model for solar PV is shown in [14], [15]; its full implementation to CorRES is ongoing. Forecast error simulation is a crucial part of the second and third case study.

\section{Comparison to historical data}

The application of WRF reanalysis data in large-scale wind and solar PV generation simulation has been shown, e.g., in [7], [8], [36]. Although they show a good fit to historical data in terms of spatial and temporal dependencies, further calibration is carried out in terms of capacity factors.

As has been shown in [8], [9], [10], using meteorological reanalysis wind speeds directly can cause significant errors in capacity factors. To correct for this, historical capacity factor data can be used to calibrate wind speeds in CorRES. Using a similar approach to [10], WRF wind speeds are scaled to reach a given historical capacity factor target. The simplest scaling is to multiply wind speeds in a region (usually one country) to reach the target capacity factor. The multipliers for the different regions are estimated iteratively. 


\section{CASE 1: SIMULATING LARGE-SCALE WIND AND SOLAR PV GENERATION FOR ENERGY SYSTEM ANALYSIS}

The case study presented in this section looks at the additional needs for flexibility caused by the growing share of VRE generation in Denmark, Sweden, Norway, Finland, and the Baltic countries based on CorRES simulations. The countries can be seen on a map in Figure 2. A full report of the analyses can be found in [37]; however, some updates have been carried out for this paper.

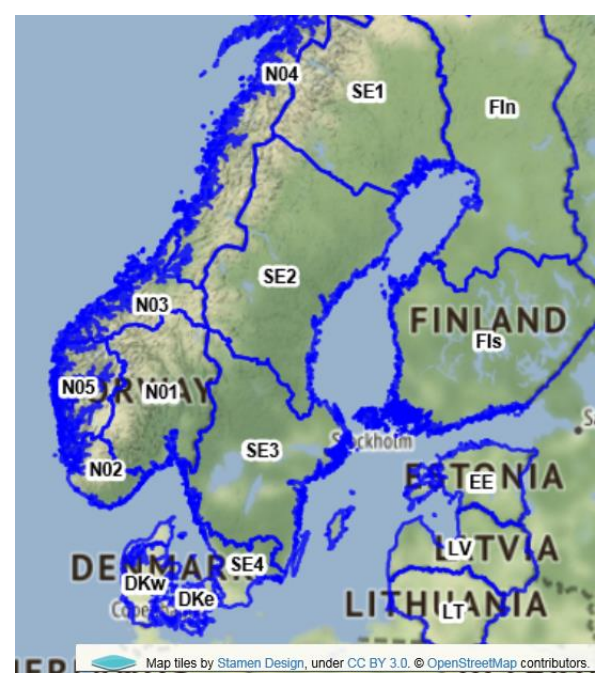

Figure 2: The analysed countries in case 1. The analysed regions are (approximately) the Nord Pool bidding areas [38], except for Finland that is divided into two areas. (c) EuroGeographics for the administrative boundaries; regions are combined of the EU Nomenclature of territorial units for statistics (NUTS) classification.

\section{VRE simulations for the analysed scenario}

VRE generation variability is analysed using installed capacities for scenario years 2020, 2030 and 2050, and for 2014. Aggregate installed capacities are presented in Table 1, with detailed data shown in Appendix A. The scenarios are the baseline scenarios from [39], with an additional modified 2050 scenario which is explained later. The modified 2050 scenario is an addition to the analyses shown in [37]. Another change compared to [37] is that Danish wind generation has been recalibrated using data from [40] (calibration is carried out as explained in the section Comparison to historical data). More information about capacity factor calibration is given in Appendix B. All time series are analysed on the hourly level. The results are based on current generation technology; this is discussed more in the section Extension of the first case study.

The geographical distribution of installed VRE generation has a significant effect on the probability distribution of the aggregate VRE generation [3], [5]. In the analysed scenarios, a notable increase in geographical distribution takes place from 2014 until 2020; however, after 2020 the overall distribution does not change significantly [37]. This can be seen as a reduction of the standard deviation (STD) divided by mean (relative STD) from 2014 to 2020 in Table 1, but with no significant change in relative STD from scenario 2020 to the baseline 2050 scenario.

As can be seen in Table 1, the baseline scenarios from [39] include very little offshore wind or solar PV installations after 2020; almost all VRE installations are assumed to be onshore wind. The correlation between solar PV and wind generation is generally slightly negative, which can reduce the variability of the aggregate VRE generation compared to only wind installations [6]. In addition, 
offshore wind has on average lower relative STD than onshore, as can be seen in Appendix C. Thus, a mix of VRE generation types can be favourable when looking at the variability of aggregate generation.

Following the approach in [41], a modified 2050 scenario was created to test the effects of increased geographical distribution of VRE installations and a more diverse mix of different VRE technologies. The modified 2050 scenario is calibrated to have the same expected aggregated annual VRE generation as the baseline 2050 scenario (using capacity factors shown in Appendix C). In the modified scenario, solar PV generates $10 \%$ of the annual VRE generation, and offshore wind has a $30 \%$ share of the expected annual wind generation. In addition, the shares of VRE installations are considered to be greater in areas geographically far away from the centre of current installations (Denmark and southern Sweden), as suggested for variance minimization in [5]; more detailed information is given in Appendix A.

As can be seen in Table 1, the modified 2050 scenario shows a significantly lower aggregate VRE generation STD than the baseline 2050 scenario. In the presented results, possible changes in VRE generation technologies in the future are not modelled. As described in the section Extension of the first case study, the future technological developments are likely to lower the relative STD.

The VRE generation ramp rates also decrease when different generation types are aggregated over a large geographical area. This is seen as an increase in the autocorrelation function (ACF) for small lags, as shown in Figure 3, which means that aggregate VRE generation is less likely to ramp up or down on successive time steps. The capabilities of the presented methodology to model temporal dependencies in VRE generation have been presented and compared to historical data in [8]. As will be shown in the next subsection, this decrease is so significant that even in the 2050 scenario the expected additional hourly ramping from VRE generation is relatively small compared to the ramping already seen in load (when measured in absolute power variability in GW).

Table 1: Installed VRE generation capacities in the scenarios, and the estimated mean and STD of the aggregate VRE generation.

\begin{tabular}{|c|c|c|c|c|c|c|c|c|}
\hline $\begin{array}{c}\text { Scenario } \\
\text { year }\end{array}$ & $\begin{array}{l}\text { Installed } \\
\text { offshore } \\
\text { wind } \\
\text { (GW) }\end{array}$ & $\begin{array}{c}\text { Installed } \\
\text { onshore } \\
\text { wind } \\
\text { (GW) }\end{array}$ & $\begin{array}{c}\text { Installed } \\
\text { solar PV } \\
\text { (GW) }\end{array}$ & $\begin{array}{l}\text { Installed VRE } \\
\text { generation } \\
\text { (\% of peak } \\
\text { load) }\end{array}$ & $\begin{array}{l}\text { Expected annual } \\
\text { VRE generation } \\
\text { (\% of annual } \\
\text { consumption) }\end{array}$ & $\begin{array}{c}\text { Mean of } \\
\text { VRE } \\
\text { generation } \\
\text { (GW) }\end{array}$ & $\begin{array}{l}\text { STD of VRE } \\
\text { generation } \\
\text { (GW) }\end{array}$ & $\begin{array}{c}\text { STD } \\
\text { divided } \\
\text { by } \\
\text { mean }\end{array}$ \\
\hline 2014 & 1.46 & 9.78 & 0.65 & 16.2 & 7.22 & 3.42 & 2.03 & 0.594 \\
\hline 2020 & 3.56 & 15.9 & 0.99 & 27.8 & 12.7 & 6.00 & 3.19 & 0.532 \\
\hline 2030 & 3.87 & 30.6 & 1.76 & 49.4 & 22.0 & 10.4 & 5.55 & 0.533 \\
\hline 2050 & 3.87 & 54.3 & 1.75 & 81.7 & 36.8 & 17.4 & 9.34 & 0.536 \\
\hline $\begin{array}{l}\text { Modified } \\
2050\end{array}$ & 12.5 & 38.1 & 16.5 & 91.4 & 36.8 & 17.4 & 8.00 & 0.459 \\
\hline
\end{tabular}

The capacities are the aggregates of all analysed countries. The scenarios until 2050 are the baseline scenarios from [39]. The modified 2050 scenario gives the same expected annual VRE generation as the baseline 2050 scenario (more details can be found in Appendix A). The comparisons to load are calculated using 2012 load data. The VRE generation means and STDs are estimated using five years of CorRES simulations (capacity factors are shown in Appendix C). 


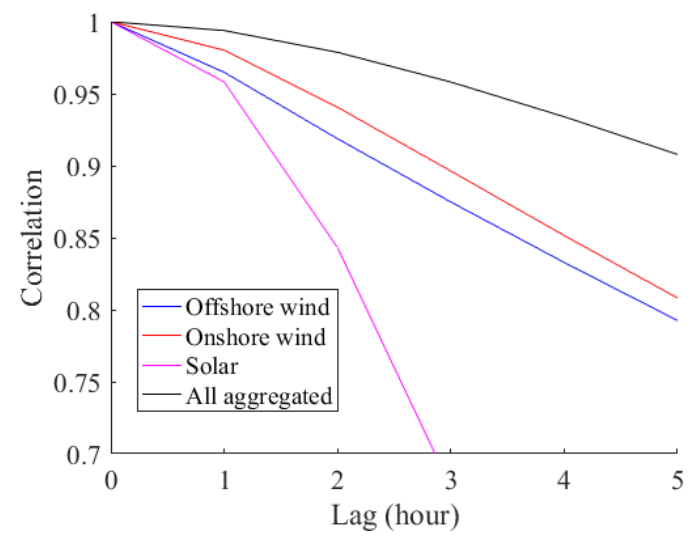

Figure 3: Average autocorrelation functions (ACFs) of the different VRE generation types of all the analysed areas, and ACF of the aggregate VRE generation in the 2014 scenario. All ACFs are estimated from the five years of simulated VRE generation data from CorRES.

\section{Variability in residual load and needs for flexibility}

Aggregate load and VRE generation for an example scenario year are shown in Figure 4; load data was acquired from the European Network of Transmission System Operators (ENTSO-E) [42]. To get the VRE generation time series shown in the figure, each region was modelled with the VRE installation shown in Appendix A for scenario 2050. CorRES was then used to model what these VRE installations would have generated in meteorological year 2012.

It can be seen in Table 2 that the mean of the residual load decreases as installed VRE generation capacity increases. The $95^{\text {th }}$ and the $99^{\text {th }}$ percentiles also decrease, but less than the mean. From 2014 to the baseline 2050 scenario, the mean decreases by $13.6 \mathrm{GW}$ and the $95^{\text {th }}$ and $99^{\text {th }}$ percentiles by $10.9 \mathrm{GW}$ and $8.0 \mathrm{GW}$, respectively. This means that the expected annual generation from sources other than wind and solar PV decrease significantly. However, there are many hours when generation from these other sources are required. E.g., storage and demand-side response [43], and transmission of power to and from other countries can also be utilised to provide the required flexibility.

The increase in the residual load volatility is also seen as increasing STD in Table 2 when going from 2014 to the baseline 2050 scenario. The modified 2050 scenario shows lower STD than the baseline 2050 scenario. However, as a percentage the reduction is less than in aggregate VRE generation STD shown in Table 1. A contributing factor are the different correlations between load and wind generation, and load and solar PV generation [41]. 


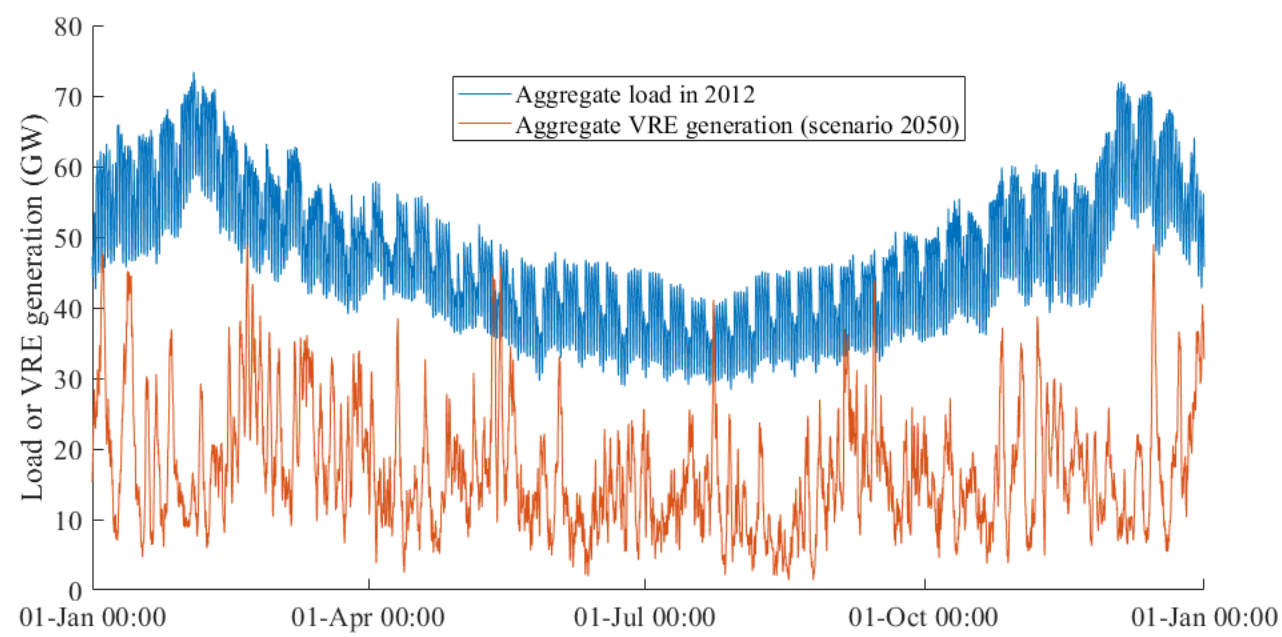

Figure 4. The aggregate load time series of 2012 and the aggregate VRE generation of the 2050 scenario for the analysed Nordic and Baltic countries. The VRE generation is simulated for the VRE installation scenario 2050 using historical meteorological year of 2012.

Table 2: Descriptive statistics for aggregate load, and residual load in the different scenarios.

\begin{tabular}{|c|c|c|c|c|c|}
\hline Scenario year & Mean (GW) & STD (GW) & 5 $^{\text {th }}$ percentile (GW) & 95 $^{\text {th }}$ percentile (GW) & percentile (GW) \\
\hline Only load & 47.3 & 9.5 & 33.1 & 64.8 \\
\hline 2014 & 44.0 & 9.5 & 30.4 & 69.9 \\
\hline 2020 & 41.5 & 9.4 & 28.2 & 56.0 & 66.0 \\
\hline 2030 & 37.2 & 9.8 & 23.3 & 51.3 & 63.5 \\
\hline 2050 & 30.4 & 11.4 & 12.9 & 50.1 \\
\hline Modified 2050 & 30.4 & 11.0 & 14.3 & 59.6 & 5 \\
\hline
\end{tabular}

The first row describes the variability in 2012 aggregate load. The other rows describe the residual load for the different scenario years (using 2012 meteorological data).

Ramp rates ( $1^{\text {st }}$ difference) of the aggregate load and the residual load for the different scenarios are presented in Figure 5 and Table 3. Compared to the hourly ramp rates in load, the increasing VRE generation does not significantly increase the ramp rates in residual load in any scenario. There is a modest increase in 2050, as STD of the residual load ramp rate is expected to be $14 \%$ higher than today (2014). However, as the number of online conventional generation units decrease, the ramping required from the remaining units can increase significantly. In the modified 2050 scenario, the ramp rate STD is significantly lower than in the baseline 2050 scenario. Extension of the study using multiple years of residual load data is discussed in the section Extension of the first case study. 


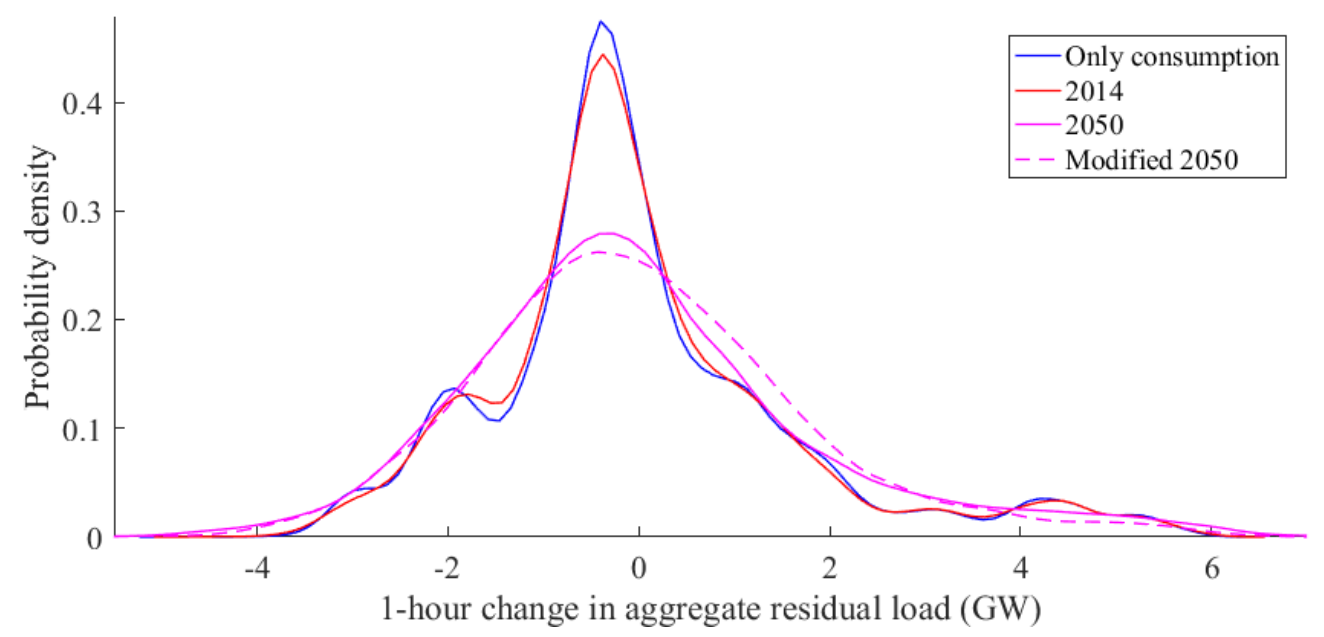

Figure 5. The estimated PDF of the $1^{\text {st }}$ difference of aggregate load and residual load for the 2014 , baseline 2050 and modified 2050 scenarios (using 2012 meteorological and load data). The PDF estimation is carried out using standard kernel estimation in Matlab [44].

Table 3: Descriptive statistics for the $1^{\text {st }}$ difference of the aggregate load and residual load in the scenarios.

\begin{tabular}{|c|c|c|c|}
\hline Scenario year & STD (GW) & 5th percentile (GW) & 95th percentile (GW) \\
\hline Only load & 1.63 & -2.28 & 3.62 \\
\hline 2014 & 1.62 & -2.29 & 3.62 \\
\hline 2020 & 1.62 & -2.27 & 3.53 \\
\hline 2030 & 1.65 & -2.33 & 3.71 \\
\hline 2050 & 1.84 & -2.58 & 3.09 \\
\hline Modified 2050 & 1.70 & -2.54 & \\
\hline
\end{tabular}

The first row describes ramp rates in the 2012 aggregate load, and the other rows present the expected ramp rates in residual load in the different scenarios (using 2012 meteorological and load data).

\section{APPLICATION OF SIMULATED LARGE-SCALE WIND AND SOLAR PV GENERATION FOR POWER SYSTEM OPERATION, PLANNING AND ANALYSIS}

This section presents case studies 2 and 3. While case 1 demonstrated the application of CorRES in energy system analysis, cases 2 and 3 mainly deal with power system operation, planning and analysis. CorRES can support different aspects of power system analysis beginning from long-term power system planning to real-time operational studies.

\section{Case 2: Reserve requirements for balancing wind power forecast errors}

An example of long term system planning is estimation of adequacy of reserves in a system with high penetration of renewables [11]. Generally, the operation of power systems are planned day-ahead of the operation using day-ahead forecasts of renewable generations. Closer to real time operation, forecast errors reduce allowing the operators make judicial choices and activate reserves to handle forecast errors. During real time operation, imbalances are handled using automatic reserves. However, detailed multi-year simulation of VRE generation time series and forecast errors at different locations for different time horizons (day-ahead, hour-ahead and intra-hour prognoses) and real-time generation are required for estimating these reserves. Tools like CorRES are required, 
since only hourly WRF data without the simulation of fluctuations (needed for representative intrahour simulations) and forecast errors would not be suitable and sufficient for these kinds of studies.

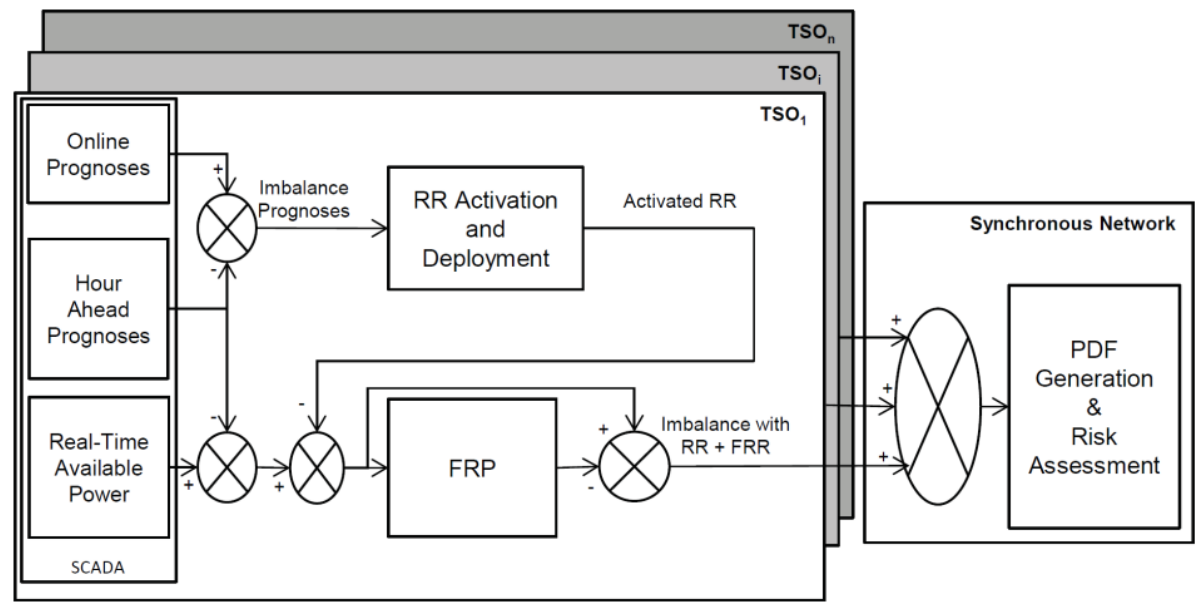

Figure 6: Flowchart for estimating adequacy of reserves for handling wind power imbalance [11].

Figure 6 shows the flowchart for estimating adequacy of reserves for handling hour-ahead wind power imbalances. At the beginning of operating hour, each transmission system operator (TSO) is assumed to balance their system using tertiary or replacement reserves (RR). When online prognoses of wind power are obtained from CorRES, emulating supervisory control and data acquisition (SCADA), the imbalance prognoses are compared to the hour-ahead prognoses. If these imbalance prognoses exceed certain pre-defined values, RR are activated and deployed to handle the imbalance in real-time. However, these activated RR can be insufficient or counter-productive to handle real-time imbalances that are handled using automatic primary or frequency containment reserves (FCR) and secondary or frequency restoration reserves (FRR). Detailed mathematical and operational analysis can be found in [11].

Time series for future wind power scenarios for Continental European (CE) were simulated using CorRES. CE is designed to operate with $3000 \mathrm{MW}$ of primary reserves in order to handle unforeseen disturbances. Therefore, it should be made sure that imbalances created by wind power forecast error must not utilize this reserved power in order to maintain reliability of the system [11]. It should be noted that in order to increase the volume of automatic primary reserves beyond $3000 \mathrm{MW}$ for future CE network, the operational and balancing cost would increase. Therefore, it is general endeavour from the TSOs to retain the primary reserve requirement to $3000 \mathrm{MW}$ and only increase this volume when other reserve options like market based tertiary reserves/replacement reserves or slower secondary reserves/frequency restoration reserves are insufficient.

Figure 7 shows the probability of imbalance exceeding $3000 \mathrm{MW}$ due to wind power forecast error for 2020 and 2030 wind power scenarios in CE. From these results, it can be observed that although imbalance due to wind power forecast error is foreseen to be low in 2020, it can be expected to be quite high in the 2030 scenario. However, these imbalances can be substantially reduced by increasing the volume of secondary reserves or FRR [11]. Volume of secondary reserves is represented as percentage of recommended secondary reserves. Secondary reserve requirement for each control area is computed by either empirical or probabilistic method dependent on peak load of the control area as given in [45]. Recommended secondary reserves are computed based on these methods for future load scenarios for each control area. 


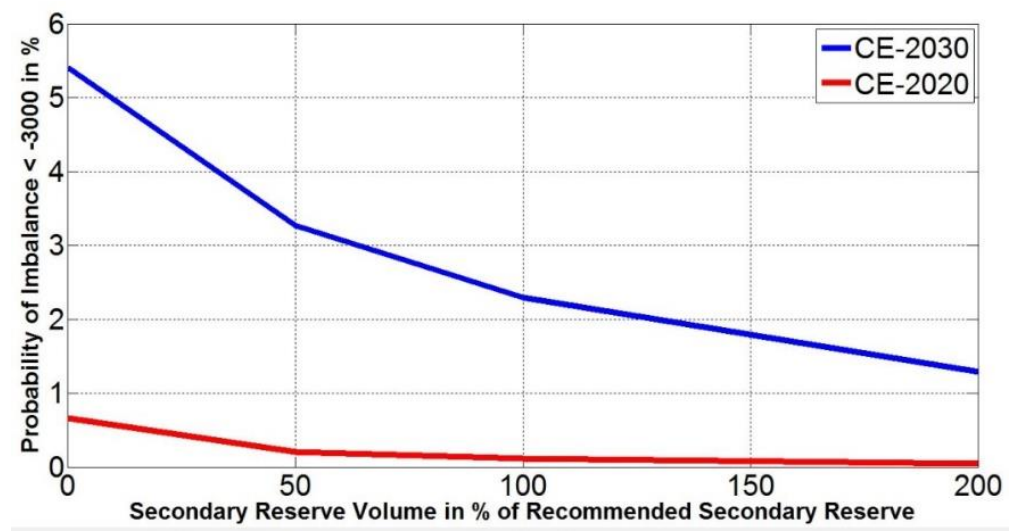

Figure 7: Probability of wind power imbalance more than $3000 \mathrm{MW}$ for CE in 2020 and 2030.

\section{Case 3: Security and stability of high wind power penetrated power system during storm conditions}

While the previous case study was long-term planning for handling wind power forecast uncertainties, this case deals with short-term operational planning of power system. Spatiotemporal simulations of renewable power generations including power fluctuations allow the study of shortterm effects. These data are highly valuable if the study is related to short-term events such as storms. One such analysis is security and stability studies of high wind power penetrated power system during storm conditions, which is discussed in this subsection. Note that the results presented are from studies performed in [46].

The study involves application of historical extreme weather condition (storm) data to the future highly wind penetrated Western Denmark power system and analyse the probable power imbalance caused by the shutting down of wind power plants due to this event. Realistic and coherent wind production imbalances under extreme weather conditions are therefore simulated using CorRES, accounting for the spatial distribution and temporal behaviour of the wind speeds.

An historical severe storm event happened in $8^{\text {th }}$ January 2005, which is considered for this study case. This storm was one of the worst storms after 1999 [47]. The strongest measured 10 minutes average wind speed reached as high as $35 \mathrm{~m} / \mathrm{s}$. CorRES simulations show that the wind speeds at Danish wind farms - Horns Rev (HR) 1,2 and 3 wind farms exceed $25 \mathrm{~m} / \mathrm{s}$ firstly. After 16:00, almost all wind speeds seen by wind farms exceed $24 \mathrm{~m} / \mathrm{s}$. The simulated wind power with High Wind Shut Down (HWSD) control [48] is shown in Figure 8, from which it can be seen that a large prediction error occurs from 5:00 to 6:00. This error is mainly due to the shutting down of three large offshore wind farms: HR 1, 2 and 3, and some near-shore wind farms. Because of a small geographical distribution, the wind speeds at these three offshore farms reach $25 \mathrm{~m} / \mathrm{s}$ almost simultaneously. As a result, the wind power drops with a relatively large gradient of around $1100 \mathrm{MW} / \mathrm{h}$. 


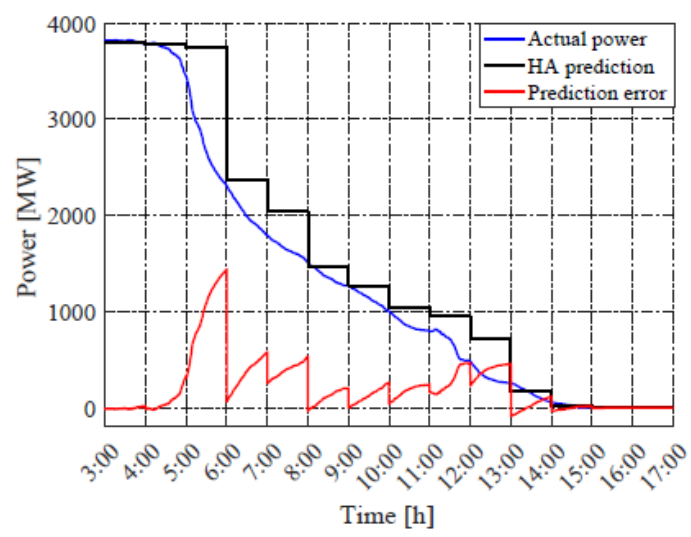

Figure 8. Simulated actual wind generation (with HWSD control), hour-ahead (HA) prediction and the prediction error in Western Denmark during the studied storm case.

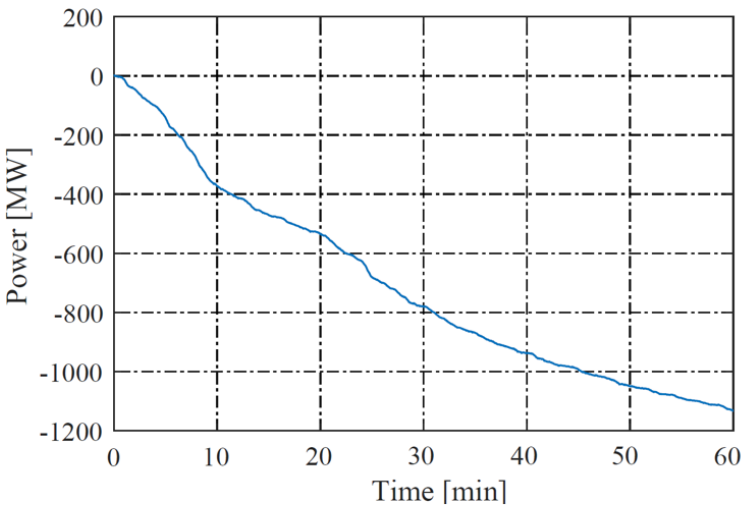

(a)

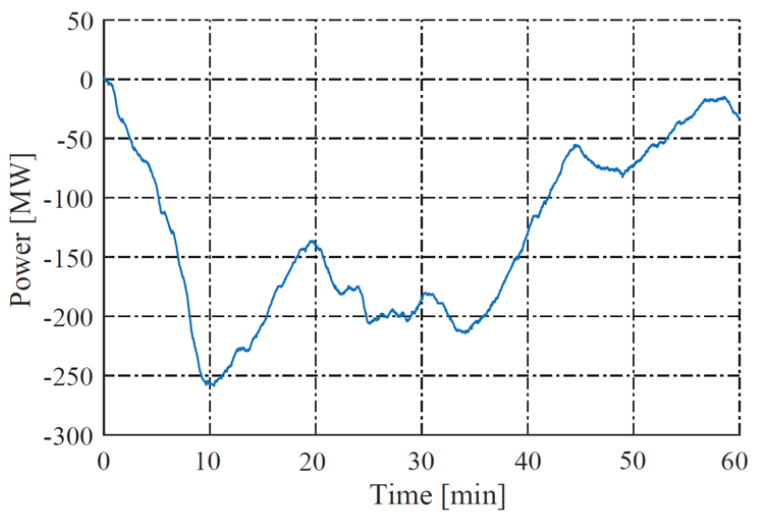

(c)

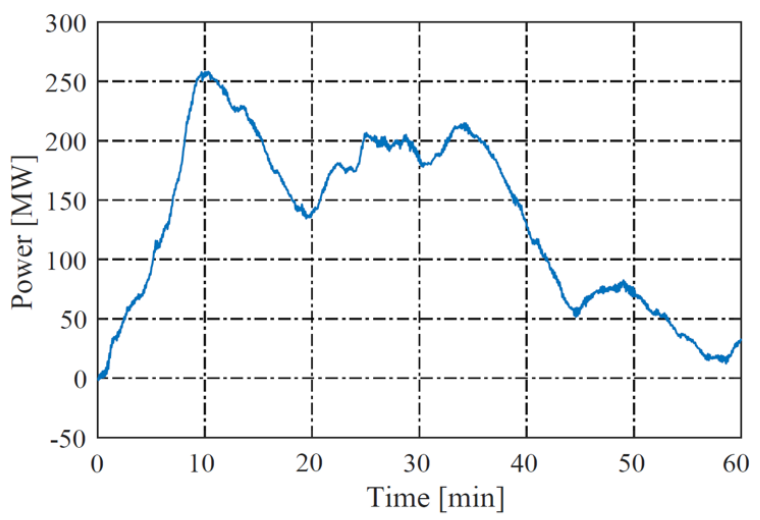

(b)

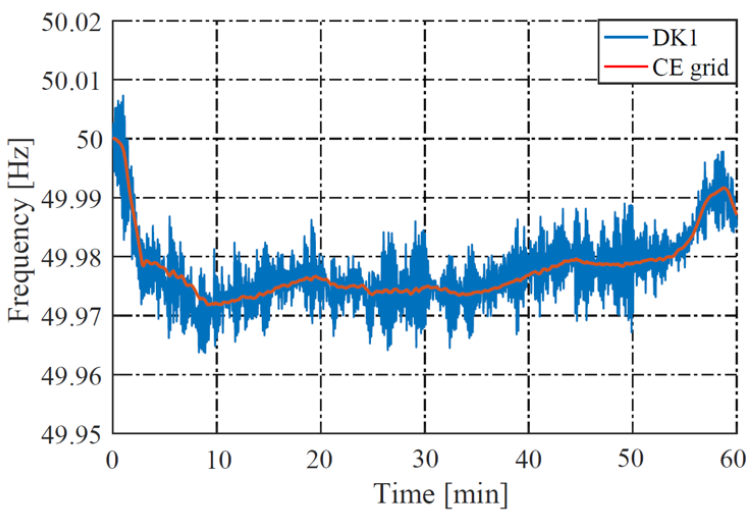

(d)

Figure 9. Frequency control during severe storm. (a) Deviation of total wind power in DK1 (western Denmark), (b) Change in power imported from Germany, (c) Generation imbalance in DK1 system, and (d) System frequency.

Impact of the described power drop of $1100 \mathrm{MW} / \mathrm{h}$ on frequency is shown in Figure 9. Detailed analysis [46] of the power drop is performed using dynamic power system model of Western Denmark (DK1) power system with wind generation input from CorRES. Dynamic power system modelling includes modelling of generations such as combined heat and power plant (CHP), decentralised heat and power plant (DCHP), wind turbines, solar photovoltaics as well as high voltage direct current interconnections to neighbouring regions and $\mathrm{AC}$ interconnections to Germany. Utilising simulated CorRES wind generation and forecast error time series in the dynamic power system model of Western Denmark, the simulations show that the power drop due to wind farms shutting down does not result in an instable or unsecured power system [46]. The main reason 
for this is that the power imbalance coming from wind is rather slow and the strong AC connection with the main Continental European network helps compensating this imbalance. Figure 9 (a) shows the total power reduction in the considered DK1 system due to shut down of the wind power plants. This reduction of power, as mentioned before, is compensated by the power flow from Germany power network (Figure 9 (b)) resulting in reduction of power imbalance in DK1 (Figure 9 (c)). The resulting power imbalance is not enough to create large drop in frequency as evident from Figure 9 (d). The reserved capacities on the interconnectors are important for this compensation to ensure that the interconnectors are not overloaded when extra power is delivered from Germany to Western Denmark to support the wind generation loss.

\section{DISCUSSION}

This section provides further discussion on the presented case studies, focusing on possible extensions for future research.

\section{Extension of the first case study}

The VRE generation simulations presented in the section Case 1: Simulating large-scale wind and solar PV generation for energy system analysis are based on modelling assuming current generation technology. Thus, e.g., increasing hub heights of wind power plants are not modelled for the future scenarios. Ongoing work aims to model these changes, leading to increasing capacity factors for the future years.

In future research, the analysis of residual load for one year will be extended to multiple years using more load data (VRE generation simulations are available for tens of years). This will give more reliable estimates of the residual load statistics, especially the high and low percentiles presented in Table 2 and Table 3. In addition to using historical load data, stochastic time series modelling of load will be considered. Such models enable simulations of large amounts of load time series, which can be used together with VRE generation time series to give, e.g., a probabilistic estimate of peak residual load [49].

\section{Extension of the second case study}

In the presented case study of reserve estimation (case 2), the system is assumed to be balanced before hour-ahead operation. In practice, this is generally not true due to forecast error of dayahead forecasts. However, inter-hour balancing is done to minimize this error which has impact on the availability of RR. In future studies, real-time availability of RR should be considered while estimating the adequacy of FCR and FRR.

Power system components such as lines are vulnerable to disconnection during storm events. Disconnection of lines can sometimes render the system into islanded operation mode invoking frequency emergency. Several studies [46], [50], [51], have discussed the emergency support from wind power during such scenarios. However, such support requires the knowledge of actual wind speed and associated fluctuations seen by individual wind turbines to estimate the capability of wind turbines to support during such situations. CorRES can help in such studies providing estimation of wind speeds seen by the wind turbines. Further, generally, all these studies discount effects of 
voltage fluctuations, line congestions etc. for these events which can have substantial impact on the results of these studies.

\section{Conclusion}

This paper has shown how time series simulation of wind and solar generation can be used to analyse the variability and uncertainty in VRE generation. Example case of CorRES software, which combines meteorological time series and stochastic simulation, was used to show how time series simulation can be used in addressing the challenges posed by the increasing share of VRE generation, such as power system security and stability, transmission system planning and electricity market studies. The tool can be used to model both today and future scenarios with varying VRE installations.

The application of VRE time series simulation was demonstrated through three case studies. The first study looked at the expected effects of the increasing VRE generation installations in future Nordic and Baltic scenarios. The increasing VRE generation is not expected to increase the hourly ramp rates in the residual load significantly. The STD of the residual load increases slightly in 2030, and notably in the baseline 2050 scenario. At the same time, the mean of the residual load decreases. There will thus be less energy to be generated by the other generation types, while the need for flexibility increases. It was shown that a modified 2050 scenario, with a more diverse geographical distribution of installations and mix of different VRE technologies, shows a much lower relative STD of aggregate VRE generation than the baseline 2050 scenario.

As some VRE generation is usually available during peak load, the probability of very high residual load is expected to decrease in future scenarios. However, there is always some probability that the aggregate VRE generation is very low, and thus the highest possible residual load is determined by peak load. This may raise questions considering the incentives to hold enough other generation capacity to meet the rare peak residual load (e.g., demand-side response can also be used). The analysis of peak residual load is an important topic in the Nordic countries [52].

The second and third case studies dealt with the impact of short-term forecast errors and spatiotemporal correlations of wind generation on power system planning, operation and analysis. Spatiotemporal simulations of VRE generations, including power fluctuations, can be imperative for operational and planning decisions such as reserve estimation and stability analysis, as seen in the presented case studies.

\section{Acknowledgments}

The authors would like to acknowledge support from the Danish Energy Technology Development and Demonstration Programme (EUDP) IEA WIND Task 25 (Danish Energy Agency, grant 640150016), and the Flex4RES (Nordic Energy Research, grant 76084) and NSON-DK (Danish Energy Agency, EUDP, grant 64018-0032, previously ForskEL) projects.

\section{References}

[1] H. Louie, "Correlation and statistical characteristics of aggregate wind power in large transcontinental systems," Wind Energy, vol. 17, no. 6, pp. 793-810, June 2014.

[2] A. Malvaldi, S. Weiss, D. Infield, J. Browell, P. Leahy and A. M. Foley, "A spatial and temporal correlation analysis of aggregate wind power in an ideally interconnected Europe," Wind Energy, vol. 20, no. 8, pp. 1315-1329, March 2017. 
[3] J. Kiviluoma, H. Holttinen, D. Weir, R. Scharff, L. Söder, N. Menemenlis, N. A. Cutululis, I. Danti Lopez, E. Lannoye, A. Estanqueiro, E. Gomez-Lazaro, Q. Zhang, J. Bai, Y.-H. Wan and Mill, "Variability in large-scale wind power generation," Wind Energy, vol. 19, no. 9, pp. 1649-1665, September 2016.

[4] B. Klöckl and G. Papaefthymiou, "Multivariate time series models for studies on stochastic generators in power systems," Electric Power Systems Research, vol. 80, no. 3, pp. 265-276, March 2010.

[5] M. Koivisto, J. Ekström, J. Seppänen, I. Mellin, J. Millar and L. Haarla, "A statistical model for comparing future wind power scenarios with varying geographical distribution of installed generation capacity," Wind Energy, vol. 19, no. 4, p. 665-679, April 2016.

[6] J. Ekström, M. Koivisto, I. Mellin, R. J. Millar and M. Lehtonen, "A Statistical Model for Hourly Large-Scale Wind and Photovoltaic Generation in New Locations," IEEE Transactions on Sustainable Energy, vol. 8, no. 4, pp. 1383-1393, March 2017.

[7] M. Marinelli, P. Maule, A. N. Hahmann, O. Gehrke, P. B. Nørgård and N. A. Cutululis, "Wind and Photovoltaic Large-Scale Regional Models for Hourly Production Evaluation," IEEE Transactions on Sustainable Energy, vol. 6, no. 3, pp. 916-923, July 2015.

[8] E. Nuño, P. Maule, A. Hahmann, N. Cutululis, P. Sørensen and I. Karagali, "Simulation of transcontinental wind and solar PV generation time series," Renewable Energy, vol. 118, pp. 425-436, April 2018.

[9] I. González-Aparicio, F. Monforti, P. Volker, A. Zucker, F. Careri, T. Huld and J. Badger, "Simulating European wind power generation applying statistical downscaling to reanalysis data," Applied Energy, vol. 199, pp. 155-168, August 2017.

[10] I. Staffell and S. Pfenninger, "Using bias-corrected reanalysis to simulate current and future wind power output," Energy, vol. 114, pp. 1224-1239, November 2016.

[11] K. Das, M. Litong-Palima, P. Maule, M. Altin, A. D. Hansen, P. E. Sørensen and H. Abildgaard, "Adequacy of frequency reserves for high wind power generation," IET Renewable Power Generation, vol. 11, no. 8, pp. 1286-1294, 2017.

[12] D. Flynn, Z. H. Rather, A. Ardal, S. Darco, A. D. Hansen, N. A. Cutululis, P. E. Sørensen, A. Estanqueiro, E. Gomez, N. Menemenlis, C. Smith and Y. Wang, "Technical impacts of high penetration levels of wind power on power system stability," WIREs Energy and Environment, vol. 6, no. 2, p. March/April, 2017.

[13] T. Traber, H. Koduvere and M. Koivisto, "Impacts of offshore grid developments in the North Sea region on market values by 2050: How will offshore wind farms and transmission lines pay?," in European Energy Market (EEM), 2017 14th International Conference on the, Dresden, Germany, 2017.

[14] E. Nuño, M. Koivisto, N. Cutululis and P. Sørensen, "On the simulation of aggregated solar PV forecast errors," IEEE Transactions on Sustainable Energy, Early Access article (DOI: 10.1109/TSTE.2018.2818727).

[15] E. Nuño, M. Koivisto, N. Cutululis and P. Sørensen, "Simulation of regional day-ahead PV power forecast scenarios," in PowerTech, 2017 IEEE Manchester, Manchester, UK, 2017.

[16] M. Koivisto, J. Seppänen, I. Mellin, J. Ekström, J. Millar, I. Mammarella, M. Komppula and M. Lehtonen, “Wind speed modeling using a vector autoregressive process with a time-dependent intercept term," International Journal of Electrical Power \& Energy Systems, vol. 77, pp. 91-99, May 2016.

[17] S. Alessandrinia, L. D. Monache, S. Sperati and G. Cervone, "An analog ensemble for short-term probabilistic solar power forecast," Applied Energy, vol. 157, no. 1, p. 95-110, November 2015.

[18] S. S. Soman, H. Zareipour, O. Malik and P. Mandal, "A review of wind power and wind speed forecasting methods with different time horizons," in North American Power Symposium (NAPS), 2010, Arlington, TX, USA, 2010.

[19] L. Söder, "Simulation of wind speed forecast errors for operation planning of multiarea power systems," in Probabilistic Methods Applied to Power Systems, 2004 International Conference on, Ames, IA, USA , 2005.

[20] J. Olauson and M. Bergkvist, "Modelling the Swedish wind power production using MERRA reanalysis data," Renewable Energy, vol. 76, pp. 717-725, April 2015.

[21] D. Cannon, D. Brayshaw, J. Methven, P. Coker and D. Lenaghan, "Using reanalysis data to quantify extreme wind power generation statistics: A 33 year case study in Great Britain," Renewable Energy, pp. 767-778, March 2015.

[22] C. Tejeda, C. Gallardo, M. Domínguez, M. Á. Gaertner, G. C and M. d. Castro, “Using wind velocity estimated from a reanalysis to minimize the variability of aggregated wind farm production over Europe," Wind Energy, vol. 21, no. 3, pp. 174-183, March 2018.

[23] N. S. Thomaidis, F. J. Santos-Alamillos, D. Pozo-Vázquez and J. Usaola-García, "Optimal management of wind and solar energy resources," Computers \& Operations Research, vol. 66, pp. 284-291, February 2016.

[24] D. Huertas-Hernando, H. Farahmand, H. Holttinen, J. Kiviluoma, E. Rinne, L. Söder, M. Milligan, E. Ibanez, S. M. Martínez, E. GomezLazaro, A. Estanqueiro, L. Rodrigues, L. Carr, S. van Roon, A. G. Orths and e. al., "Hydro power flexibility for power systems with variable renewable energy sources: an IEA Task 25 collaboration," WIREs Energy Environment, vol. 6, no. 2, March/April 2017.

[25] W.-P. Schill, "Residual load, renewable surplus generation and storage requirements in Germany," Energy Policy, vol. 73, pp. 65-79, October 2014.

[26] F. Ueckerdt, R. Brecha and G. Luderer, "Analyzing major challenges of wind and solar variability in power systems," Renewable Energy, vol. 81, pp. 1-10, Sptember 2015.

[27] M. Koivisto, P. Heine, I. Mellin and M. Lehtonen, "Clustering of Connection Points and Load Modeling in Distribution Systems," IEEE Transactions on Power Systems, vol. 28, no. 2, pp. 1255-1265, May 2013. 
[28] W. Skamarock, J. Klemp, J. Dudhia, D. Gill, D. Barker, M. Duda, X. Huang, W. Wang and J. Powers, "description of the advanced research WRF version 3," Boulder, Colorado, USA, 2008.

[29] A. N. Hahmann, D. Rostkier-Edelstein, T. T. Warner, F. Vandenberghe, Y. Liu, R. Babarsky and S. P. Swerdlin, "A Reanalysis System for the Generation of Mesoscale Climatographies," Journal of Applied Meteorology and Climatology, pp. 954-972, May 2010.

[30] A. N. Hahmann, C. L. Vincent, A. Peña, J. Lange and C. B. Hasager, "Wind climate estimation using WRF model output: method and model sensitivities over the sea," International Journal of Climatology, vol. 35, no. 12, p. 3422-3439, October 2015.

[31] D. Dee, S. Uppala, A. Simmons, P. Berrisford, P. Poli, S. Kobayashi, U. Andrae, M. Balmaseda, G. Balsamo, P. Bauer and e. al, "The era-interim reanalysis: Configuration and performance of the data assimilation system," Quarterly Journal of the Royal Meteorological Society, pp. 553-597, April 2011.

[32] R. Frehlich and R. Sharman, "The Use of Structure Functions and Spectra from Numerical Model Output to Determine Effective Model Resolution," Monthly Weather Review, vol. 136, pp. 1537-1553, April 2008.

[33] X. G. Larsén, S. Ott, J. Badger, A. N. Hahmann and J. Mann, "Recipes for correcting the impact of effective mesoscale resolution on the estimation of extreme winds," Journal of Applied Meteorology and Climatology, pp. 521-533, March 2012.

[34] P. E. Sørensen, A. Hansen and P. Rosas, "Wind models for simulation of power fluctuations from wind farms," Journal of Wind Engineering \& Industrial Aerodynamics, vol. 90, no. 12-15, pp. 1381-1402, 2002.

[35] P. Sorensen, N. A. Cutululis, A. Vigueras-Rodriguez, L. E. Jensen, J. Hjerrild, M. H. Donovan and H. Madsen, “Power Fluctuations From Large Wind Farms," IEEE Transactions on Power Systems, vol. 22, no. 3, pp. 958-965, July 2007.

[36] E. Nuño and N. Cutululis, "Generation of large-scale PV scenarios using aggregated power curves," in Power \& Energy Society General Meeting, 2017 IEEE, Chicago, USA, 2017.

[37] M. Koivisto, P. E. Sørensen, P. Maule and E. M. Nuño, "Needs for Flexibility Caused by the Variability and Uncertainty in Wind and Solar Generation in 2020, 2030 and 2050 Scenarios," DTU Wind Energy, 2017.

[38] Nord Pool, "Nord Pool bidding areas," [Online]. Available: https://www.nordpoolgroup.com/the-power-market/Bidding-areas/. [Accessed 13 February 2018].

[39] “Nordic Energy Technology Perspectives 2016," 2016. [Online]. Available: http://www.nordicenergy.org/project/nordic-energytechnology-perspectives/. [Accessed 10 October 2017].

[40] Danish Energy Agency, “Data about Danish wind generation and installations," [Online]. Available: https://ens.dk/service/statistikdata-noegletal-og-kort/data-oversigt-over-energisektoren. [Accessed 1 February 2018].

[41] M. Koivisto, P. Maule, E. Nuño, P. Sørensen and N. Cutululis, "Statistical Analysis of Offshore Wind and other VRE Generation to Estimate the Variability in Future Residual Load," in 15th Deep Sea Offshore Wind R\&D conference, Trondheim, Norway, 2018.

[42] ENTSO-E, “ENTSO-E hourly consumption data for 2012," [Online]. Available: https://www.entsoe.eu/data/dataportal/consumption/Pages/default.aspx.

[43] A. Tuohy, B. Kaun and R. Entriken, "Storage and demand-side options for integrating wind power," WIREs Energy and Environment, vol. 3, no. 1, January/February 2014.

[44] MathWorks, "Documentation of Matlab kernel estimation," [Online]. Available: https://se.mathworks.com/help/stats/ksdensity.html. [Accessed 13 February 2018].

[45] UCTE Operations Handbook, “P1-Policy 1: Load-Frequency Control and Performance [C],” 2009. [Online]. Available: https://www.entsoe.eu/fileadmin/user_upload/_library/publications/entsoe/Operation_Handbook/Policy_1_final.pdf. [Accessed 9 6 2018].

[46] F. Guo, "Security and Stability of High Wind Penetrated Power System during Storm Conditions," Technical University of Denmark, 2017.

[47] Danish Meteorological Institute, "Danish Meteorological Institute (DMI) news article," 2005. [Online]. Available: https://www.dmi.dk/nyheder/arkiv/nyheder-2005/danmark-ramt-af-landsdaekkende-storm/. [Accessed 10 October 2017].

[48] "TWENTIES. Twenties project final report. demonstration project 4 - management of offshore wind power in extreme high wind situations (storm management)," 2013.

[49] M. Koivisto, M. Degefa, M. Ali, J. Ekström, J. Millar and M. Lehtonen, "Statistical Modeling of Aggregated Electricity Consumption and Distributed Wind Generation in Distribution Systems Using AMR Data," Electric Power Systems Research, vol. 129, pp. 217-226, December 2015.

[50] S. De Boeck, D. Van Hertem, K. Das, P. E. Sørensen, V. Trovato, J. Turunen and M. Halat, “Review of Defence Plans in Europe: Current Status, Strengths and Opportunities," CIGRE Science \& Engineering, pp. 6-16, 2016.

[51] K. Das, M. Altin, A. D. Hansen, P. Sorensen, D. Flynn and H. Abildgaard, "Wind power support during overfrequency emergency events," CIGRE Science \& Engineering, 2017.

[52] ENTSO-E, “Nordic Winter Power Balance Forecast 2017 - 2018,” [Online]. Available: https://www.entsoe.eu/Documents/Publications/SOC/Nordic/Nordic_winter_power_balance_2017-2018.pdf. [Accessed 10 February 2018]. 
[53] ENTSO-E, "Statistical Factsheet 2014," [Online]. Available:

https://www.entsoe.eu/Documents/Publications/Statistics/Factsheet/entsoe_sfs2014_web.pdf. [Accessed 10 February 2018]

[54] The Europen Wind Energy Association (now WindEurope), "Wind in power: 2014 European statistics," [Online]. Available: http://www.ewea.org/fileadmin/files/library/publications/statistics/EWEA-Annual-Statistics-2014.pdf. [Accessed 10 February 2018] 


\section{APPENDIX A: INSTALLED VRE GENERATION CAPACITIES IN THE DIFFERENT SCENARIOS}

\begin{tabular}{|c|c|c|c|c|c|c|c|c|c|c|c|c|c|c|c|c|c|c|c|c|c|c|c|c|c|c|c|c|c|c|c|c|c|c|c|c|c|c|c|c|}
\hline & \multicolumn{8}{|c|}{ Offshore wind (GW) } & \multicolumn{16}{|c|}{ Onshore wind (GW) } & \multicolumn{16}{|c|}{ Solar PV (GW) } \\
\hline Scenario & $\mathrm{Kw}$ & DKe & SE & $\mathrm{FI}$ & $\mathrm{EE}$ & LV & LT & $\mathrm{NO}$ & $\mathrm{Kw}$ & DKe & SE1 & SE2 & SE3 & SE4 & Fls & FIn & $\mathrm{EE}$ & LV & LT & NO1 & $\mathrm{NO} 2$ & NO3 & NO4 & NO5 & DKw & DKe & SE1 & SE2 & SE3 & SE4 & $\mathrm{Fls}$ & FIn & $\mathrm{EE}$ & LV & LT 1 & NO1 & $\mathrm{NO} 2$ & NO3 & NO4 & NO5 \\
\hline 2014 & 0.8 & 0.4 & 0.2 & 0.0 & 0.0 & 0.0 & 0.0 & 0.0 & 2.9 & 0.6 & 0.4 & 1.0 & 1.6 & 1.2 & 0.3 & 0.1 & 0.3 & 0.1 & 0.4 & 0.3 & 0.2 & 0.0 & 0.2 & 0.1 & 0.4 & 0.2 & 0.0 & 0.0 & 0.0 & 0.0 & 0.0 & 0.0 & 0.0 & 0.0 & 0.0 & 0.0 & 0.0 & 0.0 & 0.0 & 0.0 \\
\hline 2020 & 1.4 & 0.6 & 0.2 & 0.9 & 0.3 & 0.2 & 0.0 & 0.0 & 3.3 & 0.7 & 0.4 & 2.0 & 1.6 & 1.2 & 1.1 & 0.5 & 0.4 & 0.6 & 0.5 & 0.3 & 2.8 & 0.1 & 0.2 & 0.1 & 0.6 & 0.3 & 0.0 & 0.0 & 0.0 & 0.1 & 0.0 & 0.0 & 0.0 & 0.0 & 0.0 & 0.0 & 0.0 & 0.0 & 0.0 & 0.0 \\
\hline 2030 & & 0.6 & 0.2 & 1.2 & 0.3 & 0.2 & 0.0 & 0.0 & & 0 & 0.4 & 5.5 & 4.4 & 2 & 1.1 & 0.5 & 0.6 & 3.0 & 1.7 & 0.3 & 5.0 & 0.1 & 14 & 0.1 & & 0.3 & 0.0 & 0.0 & 0.0 & 0.1 & 0.0 & 0.0 & 0.0 & 0.0 & 0.8 & 0.0 & 0.0 & 0.0 & 0.0 & 0.0 \\
\hline 2050 & & 0. & 0.2 & 1.2 & 0.3 & 0.2 & 0.0 & 0.0 & & & 5.5 & 5.5 & 11.0 & 1.2 & 1.1 & 0.5 & 0.4 & 2.4 & 7.0 & 5.0 & 5.0 & 0.1 & 14 & 0.1 & 06 & 0.3 & 0.0 & 0.0 & 0.0 & 0.1 & 0.0 & 0.0 & 0.0 & 0.0 & 0.7 & 0.0 & 0.0 & 0.0 & 0.0 & 0.0 \\
\hline $\begin{array}{c}\text { Modified } \\
2050\end{array}$ & .0 & 1.5 & 1.5 & 1.5 & 1.0 & 1.0 & 1.0 & 3.0 & 4.0 & 1.0 & 5.0 & 5.0 & 4.5 & 1.2 & 1.1 & 2.0 & 0.6 & 3.0 & 2.0 & 2.0 & 5.0 & 0.1 & 1.4 & 0.1 & 2.0 & 1.5 & 0.0 & 0.0 & 2.0 & 2.0 & 3.0 & 0.0 & 1.0 & 1.0 & 1.0 & 0.0 & 0.0 & 1.0 & 1.0 & \\
\hline
\end{tabular}

The installed capacities for scenarios 2014 until 2050 are the baseline scenarios from [39]. The modified 2050 scenario gives the same expected annual VRE generation as the baseline 2050 scenario (using the mean values from Appendix C); however, the VRE installations are more diverse in terms of geographical spread and different VRE technologies.

\section{APPENDIX B: CAPACITY FACTORS FOR THE CALIBRATION YEAR 2014}

\begin{tabular}{|c|c|c|c|c|c|c|c|c|c|c|c|c|c|c|c|c|c|c|c|c|c|}
\hline & \multicolumn{7}{|c|}{ Offshore wind (GW) } & \multicolumn{7}{|c|}{ Onshore wind (GW) } & \multicolumn{7}{|c|}{ Solar PV (GW) } \\
\hline & DK & SE & $\mathrm{FI}$ & $\mathrm{EE}$ & LV & LT & NO & DK & SE & $\mathrm{FI}$ & $\mathrm{EE}$ & LV & LT & NO & DK & SE & $\mathrm{FI}$ & $\mathrm{EE}$ & LV & LT & NO \\
\hline $\begin{array}{c}\text { Historical } \\
2014\end{array}$ & 0.46 & & & & & & & 0.25 & 0.27 & 0.23 & 0.24 & 0.25 & 0.25 & 0.31 & & & & & & & \\
\hline $\begin{array}{c}\text { Simulated } \\
2014 \\
\end{array}$ & 0.47 & 0.33 & 0.30 & 0.29 & 0.29 & 0.40 & 0.36 & 0.25 & 0.27 & 0.23 & 0.23 & 0.25 & 0.25 & 0.31 & 0.12 & 0.10 & 0.09 & 0.12 & 0.12 & 0.12 & 0.10 \\
\hline
\end{tabular}

The historical capacity factors for 2014 are calculated for most countries by taking annual energy generation reported in [53], and installed capacities from [54] (mean of end of 2013 and end of 2014 values). For Denmark, the capacity factors are calculated using data from [40]. The numbers above are given country-wise, as historical data is available per country. For solar PV and most offshore locations, historical data was not available.

\section{APPENDIX C: BASIC STATISTICS FOR THE VRE GENERATION SOURCES}

Offshore wind (GW) Onshore wind (GW) Solar PV (GW)

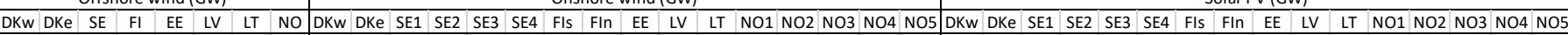
\begin{tabular}{l|lllllllll|llllllllllllllllllllllllllllllllllllll} 
Mean & 0.46 & 0.47 & 0.34 & 0.33 & 0.31 & 0.31 & 0.40 & 0.36 & 0.26 & 0.25 & 0.31 & 0.31 & 0.29 & 0.27 & 0.25 & 0.25 & 0.26 & 0.27 & 0.26 & 0.34 & 0.31 & 0.33 & 0.27 & 0.28 & 0.11 & 0.11 & 0.10 & 0.10 & 0.11 & 0.11 & 0.09 & 0.09 & 0.12 & 0.12 & 0.12 & 0.09 & 0.09 & 0.10 & 0.10 & 0.10
\end{tabular}

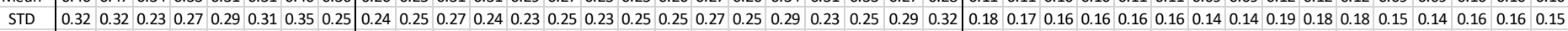

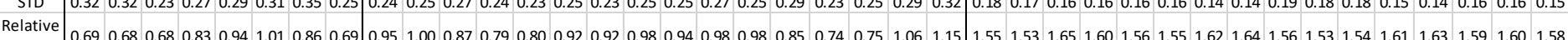

The presented values are calculated using five years (2011 to 2015) of simulated hourly VRE generation data from CorRES. As the simulations are carried out for standardized generation (i.e., values are between 0 and 1, where 1 means generation at installed capacity), the mean values are the capacity factors. 